\title{
The pervasive role of pragmatics in early language
}

\author{
Manuel Bohn \\ Department of Psychology, Stanford University, \\ Leipzig Research Center for Early Child Development, Leipzig University \\ https://orcid.org/0000-0001-6006-1348
}

\author{
Michael C. Frank \\ Department of Psychology, Stanford University \\ https://orcid.org/0000-0002-7551-4378
}

Short Title: Pragmatics in early language

Author's Note: We thank Erica Yoon and Bahar Köymen for comments on an earlier version of this paper. MB received funding from the European Union's Horizon 2020 research and innovation programme under the Marie Sklodowska-Curie grant agreement No 749229. MCF received funding from the Jacobs Foundation Research Fellowship program. Please address correspondence to mcfrank@stanford.edu. 


\begin{abstract}
Language is a fundamentally social endeavor. Pragmatics is the study of how speakers and listeners use social reasoning to go beyond the literal meanings of words to interpret language in context. In this review, we take a pragmatic perspective on language development and argue for developmental continuity between early non-verbal communication, language learning, and linguistic pragmatics. We link phenomena from these different literatures by relating them to a computational framework (the rational speech act framework), which conceptualizes communication as fundamentally inferential and grounded in social cognition. The model specifies how different information sources (linguistic utterances, social cues, common ground) are combined when making pragmatic inferences. We present evidence in favor of this inferential view and review how pragmatic reasoning supports children's learning, comprehension, and use of language.
\end{abstract}

Keywords: Language development; Social cognition; Pragmatics; Computational modeling; Communication 


\section{Introduction}

From a toddler pointing at a toy and saying "dat!" all the way to a lukewarm letter of recommendation, human beings use language to communicate an infinite range of meanings both flexibly and efficiently. Although all linguistic forms have conventional meaning within a language community, these meanings nevertheless can give rise to interpretations that are unique to the current circumstances. The term pragmatics describes this flexible use of language in context, deriving from the Greek noun $\pi \rho \tilde{\alpha} \gamma \mu \alpha$ (pragma), which refers to an act or deed. Literally, pragmatics refers to aspects of linguistic meaning that derive from the act of speaking in a particular situated context.

Human communication in context is fundamentally inferential. Because of the flexibility of pragmatic interpretation, speakers' intended meanings are always underdetermined by the linguistic forms they utter. ${ }^{1}$ For example, the same utterance ("This is my favorite") can be used to refer to very different things depending on the speaker and the context. Thus, to recover a speaker's intended meaning, a listener must combine observable information from the utterance with information about the circumstance, the speaker and their relation to the listener, and any other relevant details of the context. Because this inferential process is social in nature - its goal is to infer another agent's internal state - from a psychological perspective, pragmatic inferences are essentially an application of social cognition (Shafto, Goodman, \& Frank, 2012).

Anyone who has interacted with young children knows that, although their knowledge of linguistic forms and conventions is imperfect, they can communicate quite effectively. How do communicative abilities emerge and develop during infancy and early childhood? A rich research

\footnotetext{
${ }^{1}$ We use the terms "language," "speaker," "utterance" and "word" to refer to any kind of conventional symbolic system, independent of the modality of expression.
} 
tradition links the emergence of communication and the processes of language acquisition. Researchers in this tradition argue that children learn language by reasoning about the intentions of the people who produce it. From its descriptive beginnings in work by Nelson (1973) and Bates (1976), this line of research has become an influential strand in our understanding of the processes underlying language learning (e.g., Bloom, 2002; E. V. Clark, 2009; Tomasello, 2003).

In recent years, an equally rich but newer empirical literature has used frameworks from linguistic pragmatics (e.g., Grice, 1975) as a starting point for investigating children's ability to make pragmatic inferences (e.g., Papafragou \& Musolino, 2003; Huang \& Snedeker, 2009; Stiller, Goodman, \& Frank, 2015). The focus in this second strand of work is on how children resolve linguistic ambiguities by reasoning about the speaker's intentions. Thus, both traditions emphasize the importance of social cognition for communication.

The key findings in these two literatures seem to contradict one another, however. Research on the origins of language describes one-year-olds as deeply engaged with others' intentions in communicative interactions. In contrast, research on the development of linguistic pragmatics has focused on phenomena like scalar implicature and has emphasized children's struggles with pragmatic inferences at ages three to six years. In this paper, we attempt to synthesize these sometimes-disparate literatures, relating the development of pragmatic communication from its roots in early social cognition to the sophisticated linguistic inferences available to adults.

Along the way, we have a number of interlocking goals. First, we hope to connect research on many different aspects of pragmatic inference by making use of an emerging theoretical framework for pragmatic inference, the rational speech act framework (Goodman \& 
Frank, 2016). Second, using this framework we can ask questions about the loci of developmental change. We specifically focusing on whether we see evidence for developmental changes in the core components of pragmatics, especially the extent to which inference abilities develop.

Our final goal is polemical. We argue that throughout early language development, social communication is the central organizing principle of language use. Since, as we will argue, language learning occurs in the context of use, communication is central to learning as well. And since the core of this kind of communication is inference about unseen goals, then all language learning occurs in an inferential, pragmatic context. Thus, pragmatics plays a pervasive role in early language learning, such that the theoretical framework for pragmatic inference that we use here can also be thought of as an organizing framework for language learning more broadly. Put another way, language learning is just language use with a higher degree of uncertainty about the language itself.

Our outline is as follows. We begin our review by introducing the rational speech act framework in the context of previous theories of pragmatics. We next turn to the origins of communication in infancy ( 6 - 18 months), arguing that the evidence supports a view by which infants' early linguistic knowledge is rooted in an understanding of its communicative role. We then review how this communicative view underpins processes of early language learning (ages $1-3$ years), unifying a range of phenomena in the literature on vocabulary acquisition. We end by turning to the literature on communication and communicative inference in early childhood ( 3 - 6 years), reviewing evidence on developmental changes in pragmatic abilities. The developmental view that emerges from our review is one in which fundamental assumptions 
about the nature of communication are largely conserved through infancy and childhood, even as children's other abilities - ranging from their linguistic competence to their more general cognitive abilities - are undergoing substantial changes. This combination leads to a radical expansion of children's competence despite continuity in their assumptions about the nature of communication.

\section{What is pragmatic inference?}

A central challenge to organizing the literature on communication in early language learning is that the term "pragmatics" and its various related constructs and subcomponents mean such different things in different literatures. In some sense, interpreting the term "pragmatics" is itself a pragmatic issue! For example, some literature takes "pragmatic information" or "pragmatic cues" to mark all contextual and paralinguistic information (e.g., pointing, gesture, gaze, grounded context cues). Other literatures, in contrast, use the term as a shortening of "pragmatic inference" in the sense of Grice (1975). In what follows below, we attempt to clarify this terminological issue by being more precise about the distinction between information sources and assumptions that are used in pragmatic inferences and the computations themselves.

To do so, we begin by introducing the general approach of linguistic pragmatics. We next introduce the rational speech act (RSA) framework, which was designed to capture phenomena in this domain. RSA is a computational framework for modeling pragmatic inference that has been used to explain a wide variety of linguistic and psycholinguistic phenomena (Frank \& Goodman, 2012; Goodman \& Frank, 2016). Although we make only limited use of the computational formalism in this review, the model provides an explicit theory of language use in context that operationalizes what can otherwise be a vague and intangible set of concepts. 


\section{Linguistic pragmatics}

From a historical perspective, theories of meaning only gradually began to distinguish semantics - context-invariant or truth-conditional meaning - and pragmatics contextually-varying aspects meaning - over the course of the middle of the 20th century (Bühler, 1934; Wittgenstein, 1953; see Levelt, 2013 for a comprehensive early history). The work of H. P. Grice $(1957 ; 1975)$ played a critical role by describing a view of meaning in context as deriving from a speaker's rational use of specific utterances to convey a particular intention. Under the Gricean formulation, speakers are assumed to be rational actors who are cooperatively following a series of maxims governing communication. By making this assumption, listeners can then recover aspects of meaning that are deniable but likely, based on the speaker's assumed goals. These elements are deemed to be pragmatically "implicated," and the process of inference is known as "implicature." The inference itself can be described as counterfactual: The listener reasons that if the speaker would have wanted to express a different message, other utterances would have been better suited to do so.

In the decades following Grice, others have taken on and refined the context-sensitive view on language and communication. For example, Sperber and Wilson (2001) criticized Grice's account, with its layering and nesting of intentions, as psychologically implausible and introduced the concepts of ostension and relevance as part of developing Relevance Theory. Ostension marks an action as communicative and leads the listener to interpret it as providing relevant information. To infer the intended meaning, the listener thus asks themselves in what way the utterance is relevant to them. Their account also explicitly extended to non-linguistic forms of communication. Levinson (2000) also considered the cognitive burdens of pragmatic 
inference, asking whether some implicated meanings could be active by default. H. H. Clark (1996) situated communication in the broader context of joint action and argued that meaning is largely grounded in the structure of the overarching social interaction. And Tomasello (2008) linked the evolution of language to the phylo- and ontogenetic emergence of cooperative communication.

Although these theories have been immensely influential, they are verbal theories and hence it has been difficult to use them to make quantitative predictions. Thus, connecting them with the growing psycholinguistic literature on grounded language comprehension (e.g., Noveck \& Sperber, 2004; Katsos \& Cummins, 2010) has often proven problematic. The RSA framework that we adopt here and its predecessors in the literature on game-theoretic pragmatics (reviewed in Jäger, 2012) were designed to address this issue. RSA and its variants have now been used successfully to describe and predict a wide variety of phenomena in adult language comprehension, including implicature (Goodman \& Stuhlmüller, 2013), hyperbole (Kao et al., 2014), vagueness (Lassiter \& Goodman, 2017), generic language (Tessler \& Goodman, 2018), politeness (Yoon, Tessler, Goodman, \& Frank, 2018) and others.

\section{The Rational Speech Act Framework}

RSA is an agent-based approach to formalizing pragmatic reasoning. Listeners are modeled as reasoning recursively about the goals of speakers, and vice versa. Although the framework is explicitly designed to capture the back-and-forth of Gricean reasoning, it is consistent with much newer theorizing as well (for example, it explicitly incorporates a "relevance" distribution over possible messages). Although RSA has been used to study speaker behavior as well, we illustrate the basic RSA architecture from the perspective of a listener who 
is interpreting an utterance. The task of the listener $L$ is to estimate the probability of a particular intended message $m$ given the observed utterance $u$ by the speaker, which we notate $P_{L}(m \mid u)$. (By convention, the utterance comprises linguistic as well as non-linguistic components.) The listener is assumed to compute the posterior probability $P_{L}$ via Bayesian inference, through the integration of two components: the likelihood of the utterance given the message and the prior probability of the message:

$$
P_{L}(m \mid u) \propto P_{S}(u \mid m) P(m) .
$$

The characteristic feature of RSA is the way that the likelihood term $P_{S}$ (representing the speaker) is computed. $L$ is assumed to have an internal model of the speaker (notated $S$ ), who is modeled as choosing her utterance by maximizing her own utility. S's utility is higher the more information she transmits through her utterance (for alternative utilities, see Goodman \& Frank, 2016). Utility maximization through cooperative communication reflects the central idea that humans communicate in a relevant (Sperber \& Wilson, 2001), cooperative (H. H. Clark, 1996; Grice, 1975; Tomasello, 2008) way. This utility function can be computed in terms of whether a listener correctly inferred the intended message - producing a circularity as $L$ reasons about $S$ who in turn reasons about $L$. In practice this recursion is typically broken by a speaker reasoning about what is called a "literal listener" who only considers the (truth-functional) semantics of the message.

In addition to the recursive computation for speaker likelihood described above, listeners also take into account the prior $P(m)$, which represents evidence for (or against) a particular message, independent of the utterance. This prior term can be considered a distribution over relevant messages in context. By combining these two terms - speaker likelihood and prior - the 
listener's belief represents the outcome of a social-cognitive inference about the likely intended meaning of an utterance in context.

Taken at face value, the RSA model can seem implausibly complex or cognitively overly demanding. Although this topic is treated more extensively in other places (e.g., Goodman \& Frank, 2016), we make a number of remarks here. First, the RSA framework is a description of the computational problem being solved by agents rather than being a model of psychological process (as in the "computational level" of analysis described by Marr, 1982). Although we use the representational structure of the model as a psychological description, we do not expect particular aspects of the RSA computation to map directly onto those computations performed by language users. Second, despite this relatively limited commitment to empirical correspondence, in practice RSA models tend to provide a very good description of adults' average pragmatic inferences in schematic situations and under no time constraints. Thinking about the ways that performance might degrade under suboptimal conditions is an important goal for future work. Finally, relevant for our use of RSA in the current review, we are primarily interested in the broad decomposition of the problem of contextual language interpretation rather than the numerical predictions of the model or the specific parameter values recovered in a particular situation. Thus, for our purposes almost any Gricean or neo-Gricean account would be sufficient; we choose RSA here because its ontological commitments are most explicit.

\section{Pragmatics and grounded communication}

We next walk through a schematic case of grounded communication between two agents. (These agents could both be adults, or one could be an adult and the other could be a child learning their native language.) Figure 1 gives an overview of the different observed 
environmental variables, psychological constructs, and inferential computations posited in this framework. Importantly, although specific representational components are depicted separately, pragmatic inference in this model is a unified process in which evidence from these different sources is integrated. We find that this set of distinctions - between the information sources that enter into pragmatic inferences, the representational components of the inference, and the inferential process itself - can help clarify some of the terminological confusion surrounding whether "pragmatic cues" are truly pragmatic.

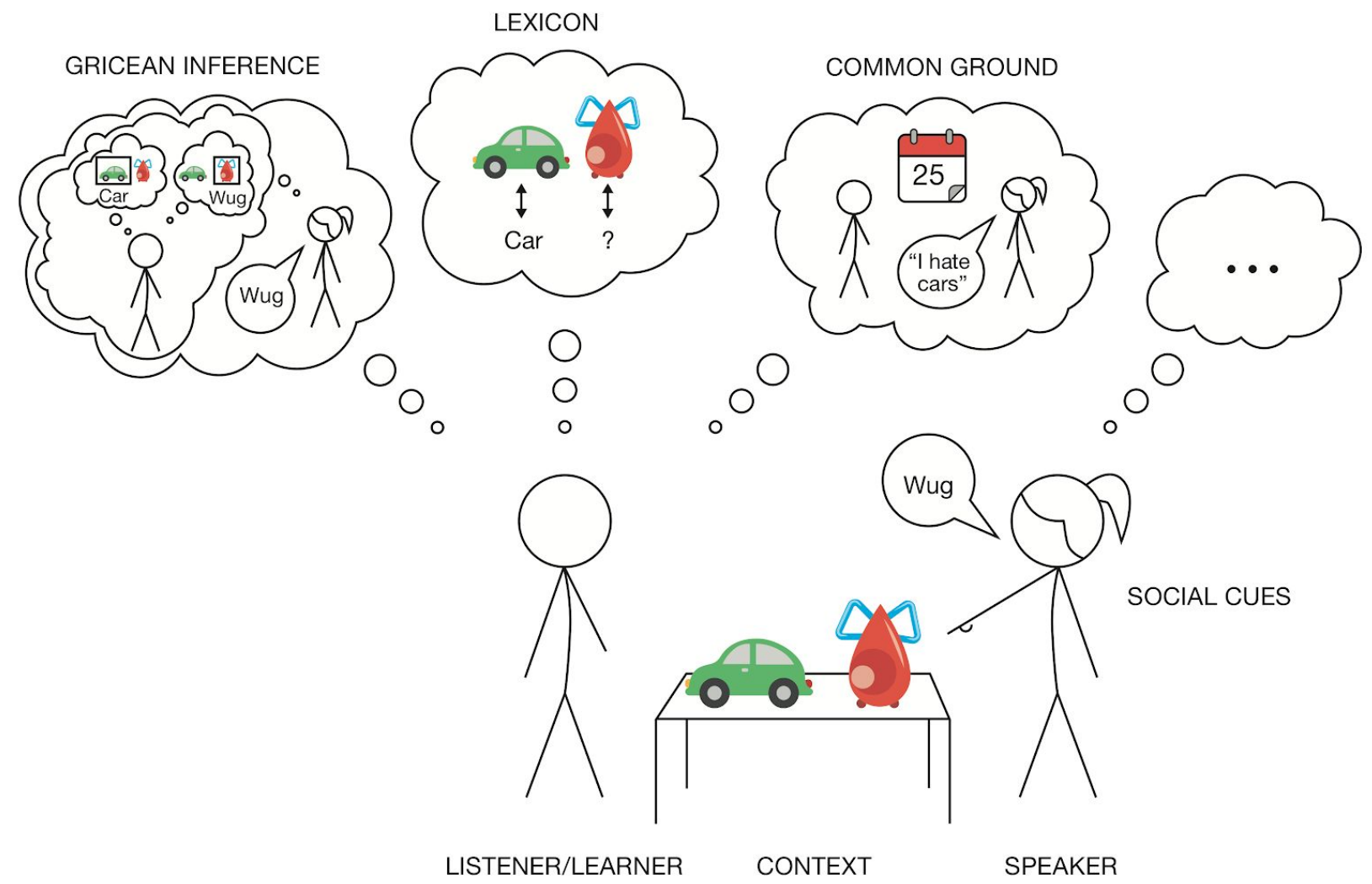

Figure 1. Schematic overview of the theoretical framework. Observable variables are the utterance, the context and additional social cues provided by the speaker. Unobserved (psychological) variables are the lexicon, common ground and the inference process. Even though components are depicted separately, we think of pragmatic inference as a unified process, during which different sources of information are integrated. 
Observable variables. The observable variables pictured in Figure 1 - those that are part of the observed physical world - can be divided into three broad groups. First, the speaker's (linguistic) utterance is observed. ${ }^{2}$ Second, the physical context of the utterance is also observed, and shapes the likely interpretation. By virtue of being perceptually available, objects in the immediate environment are more likely referents compared to absent ones. Salience due to physical characteristics and positioning relative to the conversational participants has similar effects. More broadly, contexts generate expectations about contents of utterances. For example, the word ball in "where is the ball?" will be taken to refer to very different things when asked outside a ballroom compared to on a soccer pitch. In our modeling framework, these factors affect the prior probability of a message.

Third and finally, speakers produce directly observable social cues that serve communicative functions. Examples would be orienting towards, looking at, pointing to, or touching an object. These indexical cues are often indicative to the speaker's attention and allow the listener to align their own attention to the same target as the speaker, thereby creating episodes of joint attention - mutual focus - on objects in the here and now. In principle, representational acts such as iconic gestures can serve a similar function. These social cues relate to the intended message by directly denoting a referent. Within the RSA framework, social cues are considered to be part of the utterance and supplement the literal meaning given by the

\footnotetext{
${ }^{2}$ Although the utterance itself is likely perceived by the listener with some uncertainty (e.g., as in noisy channel models of language perception: Gibson et al., 2013; Yurovsky, Case, \& Frank, 2017), for simplicity here we consider it to be observed directly.
} 
linguistic properties of the utterance. For example, if an utterance contains the word "ball" combined with a point to a ball, the message is likely to be about this particular ball. ${ }^{3}$

Unobserved (psychological) variables. These first major psychological construct posited in RSA is the lexicon, which stores conventional forms of reference. These include words or signs that are part of a language. ${ }^{1}$ The semantics given to individual parts of the lexicon is truth-functional: when applied to a particular state of affairs (a "world") they return a truth value (which is often assumed to be a probability, rather than a deterministic value, to capture that language learners have some uncertainty about what e.g. a message refers to). ${ }^{4}$

The second psychological construct in our framework is common ground. Common ground refers to bits of information that are assumed to be shared between interlocutors and constitutes the background against which utterances are interpreted (Bohn \& Köymen, 2018, H. H. Clark, 1996, E.V. Clark, 2009). Listeners expect speakers to produce relevant utterances in light of common ground. For example, imagine we are doing a puzzle together and there is one last piece missing. If I point to a place under your chair, you take this to tell you that the last piece fell under your chair, because it is part of our common ground that we are looking for the last piece. The same gesture would have a different interpretation when embedded in a different social interaction.

\footnotetext{
${ }^{3}$ Aside from providing referential information, social cues can also be used to mark actions as communicative. These ostensive cues show the listener that the current action is a communicative act that is intended to provide relevant information. We return to the issue of ostension below.

${ }^{4}$ Although we do not discuss this topic here, agents are also assumed to have combinatoric syntactic and semantic abilities such that they can create complex expressions from parts in the lexicon. The operation of pragmatic inferences in compositional utterances is an active research topic (e.g., Bergen et al., 2016; Potts et al., 2016).
} 
Common ground comes in different forms and has multiple layers (H. H. Clark, 1996).

On the one hand, objects and events that are jointly perceivable can be assumed to be part of the perceptual common ground. Events that have been jointly experienced enter personal common ground, which is specific to a dyad or a group. Finally, communal or cultural common ground refers to shared knowledge on the community level (e.g. schooling, profession, culture). In RSA models, common ground takes the form of a shared prior distribution over messages, making some messages more likely compared to others.

Inferences. The last component of RSA models is the process of reasoning that listeners go through in computing the speaker's intended message (and that speakers go through in selecting their utterances). This processes is described formally in the preceding section. One key part of this reasoning process is the comparison of alternative messages and the evaluation of whether those messages could have been expressed in less ambiguous ways compared to the utterance that the speaker used. This comparison happens within the system of recursive RSA reasoning and is pictured in the left part of Figure 1.

\section{The origins of communication in infancy}

We next turn to the developmental literature, asking whether core components of the communicative framework described above are observed during infancy. In this section, we review research on infants' language and communication in the period from 6 - 18 months. We begin by discussing the nature of the early lexicon. Next, we discuss the relationship between language and other communicative signals, primarily focusing on pointing and gestures. We end by discussing the role of ostension in communication. 


\section{The beginnings of language}

Infants produce their first words around their first birthday; vocabulary grows rapidly thereafter (Fenson et al., 1994). Early discussion of the nature of the early vocabulary tended to focus on the productive use of language (e.g., Bates, 1976; Kamhi, 1986). This large literature has been upended, however, by a growing body of evidence on infants' receptive abilities. This work suggests that, even by 6 - 9 months of age, the beginnings of receptive language are emerging (Bergelson \& Swingley, 2012; Tincoff \& Jusczyk, 1999). This evidence invites us to ask whether early language is communicative in the sense of our framework: involving inferences about the goals of social partners.

Associative accounts of early language posit that this early receptive vocabulary is not communicative in the same way as older children's language use is. That is, infants treat words not as intentionally-produced communicative acts but as regularly co-occurring properties of the objects they refer to. Sloutsky and colleagues $(2001,2017)$ embrace this associative view, highlighting the importance of spatio-temporal co-occurrence for word learning. Word learners track the statistical regularities with which words and objects co-occur and thereby build direct associations between the acoustic and visual input (Smith \& Yu, 2008). On this view social inference is at best secondary and a downstream consequence of - rather than a prerequisite for language learning. ${ }^{5}$

\footnotetext{
${ }^{5}$ A related view posits that infants around their first birthday are unable to interpret social cues as referential, making word-meaning mappings instead based on object salience. The predictive power of social cues is then learned through experience, allowing infants to "discover the intentionality" of their communicative partner (Hollich, Hirsh-Pasek \& Golinkoff, 2000). Contra this view, however, Yurovsky \& Frank (2017) found that even young infants in a simple object-mapping paradigm followed social cues to reference at very high rates; the difference was that younger children appeared less able than older children to overcome referent salience during test trials (even though they might have in principle made the correct mapping).
} 
In contrast, on the inferential continuity account that we have been sketching, even infants assume that words serve a communicative function: the speaker uses them to express a certain intention or to convey some kind of information to the speaker. Though associative accounts are prima facie plausible, several pieces of evidence now speak in favor of the view that infants treat language as intentional communication from an early age - that is, in the language of Figure 1, that both communicative gestures and lexical representations enter into pragmatic computations about intended meaning.

First, infants seem to expect communicative acts to transmit information even when they don't know the meanings of the words that are used to do so. In a striking series of demonstrations, Vouloumanos and colleagues (Vouloumanos, Onishi \& Pogue, 2012, see also Martin, Onishi \& Vouloumanos, 2012; Vouloumanos, Martin \& Onishi, 2014) had infants of 12 months and younger watch an actor trying to complete an action but fail. When an observer used unknown speech to communicate with the actor (presumably to instruct them), infants expected the actor to successfully complete the action. When the observer produced an unintentional vocalization (e.g. coughing) instead, infants had no such expectation. These results are not predicted by a view in which the early lexicon is composed of direct associative linkages.

Second, children generalize words beyond the referents they are paired with during learning. Even in the first year after birth, infants appear to encode semantic relationships in their lexicon (Bergelson \& Aslin, 2017). And shortly after their first birthday, infants expect the same word to refer to a member of a category (e.g. horses), even when the referent at test is different from the referents for which children learned the words (Booth \& Waxman, 2009; Waxman \& Markow, 1995). That is, children make inferences about what the speaker might refer to even 
when they have never encountered the particular word-object pairing during training trials. Relatedly, even younger infants use the presence of labels to individuate objects, showing surprise when a speaker uses two distinct labels to describe objects in a scene but later only one object is visible (Xu, 2002; Dewar \& Xu, 2009). Although there are plausible associative accounts of some semantic categorization phenomena in early word learning (e.g., Regier, 2003), this group of findings is parsimoniously explained by communicative accounts. For example, the use of different words signaling the presence of different objects emerges naturally from communicative word learning but not from associative accounts (Frank, Goodman, \& Tenenbaum, 2009).

Third, the use of novel signals in communicative contexts appears to lead infants to learn and generalize more from them. For example, in Ferguson \& Lew-Williams (2016), watching a conversation in which one adult communicated by "beeping" (tones were contingent on the actors mouth movements) resulted in generalization of simple repetition rules; the same result was not found when the beeps were played non-contingently over the same video. And hearing a similar communicative familiarization appeared to boost category-based attention when the tones later accompanied a set of novel objects (Ferguson \& Waxman, 2016).

Fourth, shortly after language production begins, toddlers both use and understand language for reference to absent objects, indicating that they are not simply viewing words as possible perceptual associates for objects that are present in the current context. Bates (1976) described this behavior in her case reports, and Fenson et al. (1994) reports that most parents believe their 16-month olds understand absent referents. Experimental evidence for comprehension of absent referents is present by at least 12 months (e.g., Ganea, 2005; Ganea \& 
Saylor, 2013; Osina, Saylor, \& Ganea, 2014, 2017), the same age at which infants themselves refer to absent entities using pointing gestures (Bohn, Call, \& Tomasello, 2015; Bohn, Zimmermann, Call, \& Tomasello, 2018; Liszkowski, Schäfer, Carpenter, \& Tomasello, 2009).

Finally, perhaps the strongest support for an inferential view on early communication comes from studies showing that slightly older infants' word learning is contingent on social cues provided by the speaker (e.g. Baldwin, 1993; Bottema-Beutel, 2016; Dunham, Dunham \& Curwin, 1993; Hirotani, Stets, Striano \& Friederici, 2007). For example, 18-month-olds readily learn the label for a novel toy they are engaged with when it is uttered by an experimenter who is also attending to the toy. In contrast, when the label is produced by an experimenter who is out of view, infants do not learn the label even though their own attention and the spatio-temporal contingency between label and object were the same (Baldwin, Markman, Bill, Desjardins, Irwin, \& Tidball, 1996).

Can pre-linguistic communication based on social cues like pointing, gaze, or gesture be considered inferential as well? One might argue that because posture, gaze and gesture can directly highlight objects, no additional inference is required. Comparative work with great apes provides a method to test this idea. If social cues such as gaze, points or iconic gestures were sufficient to communicate a message without any communicative inference, great apes should readily understand them. After all, great apes follow the directionality of an experimenter's gaze or point and make use of iconic relations when learning the association between a gesture and a referent (Bohn, Call \& Tomasello, 2016; Kano \& Call, 2014; Tomasello, 2008). However, when an informant (human or conspecific) uses gaze, pointing or iconic gestures in a communicative context (i.e. to indicate a food location), great apes often fail to make use of this information (e.g. 
Bohn, Call \& Tomasello, 2019; Hare, Brown, Williamson \& Tomasello, 2002; Tempelmann, Kaminski \& Liebal, 2014). In contrast, human children readily locate the reward in such contexts (Behne, Carpenter \& Tomasello, 2005; Bohn, Call \& Tomasello, 2019). Thus, while referential social cues can be used to highlight a referent, it appears to take an additional social inference to understand the intention that makes the referent relevant in context.

In sum, a variety of evidence supports the inferential view of early language and early communicative gesture. Further, because the inferential view assumes that non-linguistic and linguistic signals can be used interchangeably, it predicts continuity between infants' early communication based on social cues and later language abilities. Thus a prediction of this account is that those children who are better at using social information should also be better at learning and using language. We next turn to evidence supporting this prediction.

\section{Relationships between language and social communication}

In fact, one of the most reliable findings in the area of early language is the strong correlations between social-communicative abilities and early language. In a meta-analysis, Colonnesi and colleagues (2010) found both concurrent and longitudinal relations between infant pointing and language abilities: Children who produced more points or comprehended pointing better had higher productive and/or receptive language scores (see also Lüke, Grimminger, Rohlfing, Liszkowski, and Ritterfeld 2017). Similar evidence, on an even larger scale, comes from parent report using the MacArthur-Bates Communicative Development Inventory (CDI). In cross-linguistic adaptations of the CDI in the Wordbank database (Frank, Braginsky, Yurovsky, \& Marchman, 2016), early gestural communication was strongly correlated with early vocabulary across eight languages (Frank, Braginsky, Yurovsky, Marchman, in prep). 
This large scale evidence for relations between linguistic and non-linguistic communicative development is further corroborated by a set of smaller-scale, but more detailed, longitudinal studies. For example, Carpenter, Nagell and Tomasello (1998) studied infants between 9 and 15 month of age and found that infants who showed earlier sensitivity to social cues (gestures or gaze) started to produce referential language earlier (see also Tomasello \& Farrar, 1986). Brooks and Meltzoff $(2005,2008)$ showed that the propensity to follow other's gaze at 10 and 11 month predicted vocabulary growth throughout the second year of life. And on an even longer time scale, Rowe and Goldin-Meadow (2009) reported that differences in gesture use at 14 month related to differences in language abilities at 4.5 years of age.

In sum, this evidence supports strong ties between early non-linguistic communication and early language. But why are social cues important for learning language? We argued that social cues, like words, mark actions as communicative and also provide direct evidence for the intended message, thus these two abilities may arise from the same capacity. But there are likely other causal pathways that connect non-linguistic and linguistic communication. First, there is undoubtedly some shared variance between these two constructs that reflects general developmental advancement - thus, children who point early may speak early in part because they tend to be early for all milestones. Initial evidence against this view comes from the observation that pointing and early language are far more interrelated than they are with walking (Moore et al., 2019; cf. Walle \& Campos, 2014). Second, non-linguistic communication may create opportunities for learning, providing "bids" for labeling that caregivers respond to (e.g., Donnellan et al., 2019). Intervention research is a promising method for disentangling these relationships. 


\section{Marking communication through ostension}

We have argued that human communication is inferential from an early age; thus pragmatic inference is a special case of social inference. One sense in which communication is special is that the speaker - whose mental state has to be inferred - has a vested interest in the inference process to succeed (Shafto, Goodman, \& Frank, 2012). As a consequence, speakers should try to mark their actions as communicative to signal to the listener that a communicative inference is appropriate. So-called ostensive signals serve this function.

A substantial number of studies have shown that overtly ostensive behaviors such as eye contact or infant-directed speech lead infants and children to interpret actions as communicative. For example, 6 month old infants are more likely to follow an actor's gaze to a target when it is preceded by gaze or speech cues (Senju and Csibra, 2008). Similar results have been found in 5-7 month old infants in a non-western sample (Hernik \& Broesch, 2018). Similarly, 14-month-olds interpret a pointing gesture as communicative only when it is produced in an overtly ostensive way (Behne, Carpenter \& Tomasello, 2005). Word learning also seems to be modulated by accompanying ostensive cues (Baldwin, 1993; Egyed, Király \& Gergely, 2013) and ostensively produced pointing gestures may even override linguistic information (Grassmann \& Tomasello, 2010).

Aside from these prime examples, however, ostension is notoriously hard to define on a purely behavioral level, and children interpret acts as communicative even when they are not paired with ostensive cues. For example, 6-month-olds follow gaze in non-ostensive contexts (Szufnarowska, Rohlfing, Fawcett \& Gredebäck, 2014; Gredebäck, Astor \& Fawcett, 2018) and with some contextual framing, 2-year-olds interpret instrumental actions such as pressing a light 
switch as communicative (Moore, Mueller, Kaminski \& Tomasello, 2015). To reconcile these findings, we may say that ostensive cues are a sufficient but not necessary condition for communicative inference. This conclusion is congruent with the broader inferential framework that we propose, in which the communicative value of a particular action can serve as prima facie evidence for it being communicative (roughly "why else would they have done that other than to tell me something?").

\section{The role of pragmatics in early word learning}

The previous section reviewed how children's early communication and language are based on social cues and assumptions. Next, we turn to how these early emerging skills for inferential communication support language learning in the period from 1 to 3 years. Although there is a rich body of observational work describing this time period (see Clark \& Amaral, 2010 for review), we focus here primarily on experimental work that aims to elucidate psychological processes underlying language learning. To begin with, we want to contrast two different time scales on which word learning happens: In the moment identification of a referent and long-term learning of mappings between referents and words (items in the lexicon). At first sight, it seems appealing to view these time scales as largely independent. Psychologically, one might say that they are separate: social inferences about speaker intentions guide comprehension while statistical or associative learning processes underlie the growth of the lexicon. But we see these two components as complementary parts of a joint inference problem.

In this joint inference, in-the-moment inference is guided by lexical knowledge and the learning of lexical items depends on the degree of certainty with which the message (or at least the referent) can be identified in the moment. In other words: If you know what someone is 
talking about, it's easier to infer what specific words mean; if you know what words mean, it's easier to figure out what they are talking about. Frank, Goodman, \& Tenenbaum (2009) ${ }^{6}$ formalized this view and showed that the resulting probabilistic model predicted a broad range of phenomena characteristic of early word learning. Critically, this linkage between in-the-moment interpretation and longer-term word learning means that many phenomena that are seen as "word learning" phenomena actually occur in the context of pragmatic interpretation. A paramount example of this linkage between timescales comes from joint attention.

\section{Word learning through joint attention and common ground}

Joint attention describes situations in which two individuals are knowingly attending to the same object at the same time (Tomasello, 1995). In many cases, jointly attending to something coincides with both individuals looking at the object, combined with occasional eye-contact between them. This dense clustering of ostensive and referential social cues presents the child with an information-loaded learning opportunity, especially at the onset of lexical development around age 1. From our theoretical perspective, joint attention facilitates inference about the speaker's intention (and thereby word learning) in two complementary ways: On the one hand, a sustained attentional focus on a set of objects (or aspects of objects) increases the probability that the speaker will communicate about them later in time, changing the learner's prior. And on the other hand, attentional cues such as eye gaze provide referential information in the moment that can be interpreted as a referential part of the utterance.

Consistent with this general idea, a very robust link between joint attention and word learning has been found in a number of correlational (see Bottema-Beutel, 2016 for a recent

\footnotetext{
${ }^{6}$ See also McMurray, Horst \& Samuelson (2012) for a neural network model with similar timescale dynamics.
} 
meta-analysis) and experimental studies (e.g. Baldwin, 1993; Dunham, Dunham \& Curwin, 1993; Hirotani, Stets, Striano \& Friederici, 2007), including in non-Western samples (e.g. Childers, Vaughan \& Burquest, 2007). With increasing age, infants improve in their ability to coordinate attention with a partner (Mundy, et al., 2007). Furthermore, overt cues such as gaze or eye-contact are less important for children above age two, suggesting that children come to use other (less direct) sources of information to infer the speaker's intention (Adamson, Bakeman \& Deckner, 2004; Scofield \& Behrend, 2011).

One such information source is the common ground that is shared between interlocutors. Common ground guides inferences about interpretation because it makes some messages more likely compared to others (changing the prior probability of the message in our framework). This constraint is conditional on the identity of the speaker, however, in that what is part of common ground with one person might not be shared with another.

How do we know what is part of common ground and what is not? The most direct way in which information can be grounded is through direct social interaction. And in fact, even very young children have been found to adjust their communication to common ground established that way (Liszkowski, Carpenter \& Tomasello, 2008; Saylor, Ganea \& Vazquez, 2011). For example, 12-month-olds were more likely to refer to an absent object by pointing to its previous location if the recipient had interacted with them while the object was still in that location (Bohn, et al., 2018). Common ground established in direct social interaction also supports young children's word learning (e.g. Akhtar, Carpenter \& Tomasello, 1996; Diesendruck, Markson, Akhtar \& Reudor, 2004; Saylor, Sabbagh, Fortuna \& Troseth, 2009). 
From a conversational perspective, common ground also includes the immediate discourse context of an utterance, and the structure of the unfolding interaction thus offers cues to the speaker's intended meaning. From 2 years onwards, children interpret new words as referring to objects (or properties of objects) that are relevant given discourse context (Akhtar, 2002; Horowitz \& Frank, 2015; Sullivan, Boucher, Kiefer, Williams \& Barner, 2019). For example, when a speaker asks for "the dax" (an unknown word) after saying they are hungry, 2-year-olds choose something edible as the referent (Sullivan \& Barner, 2016). Taken together, we may say that the early emergence of sensitivity to common ground suggests that the core assumption that communicative acts are produced and interpreted in light of common ground is a developmental constant. What develops significantly are skills that allow children to determine how information comes to be part of common ground (Bohn \& Köymen, 2018). The process of adding information into common ground involves reasoning about group-specific knowledge and conventions (Srinivasan, Foushee, Bartnof \& Barner, 2019), others' perspectives (Nadig, \& Sedivy, 2002; Nilsen \& Graham, 2009), others' beliefs about the world (Southgate, Chevallier \& Csibra, 2010; Király, Oláh, Csibra \& Kovács, 2018) and eventually others' beliefs about one’s own beliefs (Grueneisen, Wyman \& Tomasello, 2015).

\section{Word learning through pragmatic inference}

A speaker's choice of words is also informative with regard to their intention: a particular word choice contrasts with what the speaker did not say but could have said. In our inferential framework, this general logic can give rise to a wide variety of word learning phenomena (often with distinct names for the phenomena in the literature). For example, in a classic study, Carey and Bartlett (1978) explicitly contrasted a novel color word with a known one ("the chromium 
one, not the green one") and showed that 3-year-olds took it to refer to an object with an unknown color. Subsequent studies removed the explicit contrast and showed that from 17 months onwards and perhaps even earlier (Markman, Wasow, \& Hansen, 2003), infants seem to expect labels to be mutually exclusive and infer that novel words refer to novel objects (e.g. Halberda, 2003; Markman \& Wachtel, 1988).

A large number of theoretical explanations have been put forward for this "mutual exclusivity" effect (see Lewis, Cristiano, Lake, Kwan \& Frank, 2019 for an overview and meta-analysis). Because of its parsimony with our general framework, we favor a pragmatic explanation as at least one possible source of the effect (E. V. Clark, 1988; E. V. Clark \& Grossman, 1998). In this account, mutual exclusivity follows from the interplay between lexical knowledge and expectations about speaker informativity. The least ambiguous way to refer to the known object would be to use the label stored in the lexicon. As a consequence, the fact that the speaker did not use the known label tells the listener that the speaker is not referring to the known object, which makes the novel object the more likely referent for the novel word (seen Frank, Goodman, \& Tenenbaum, 2009 for a formal analysis). On this view, mutual exclusivity should be tightly linked to the listener's lexical knowledge, a prediction that is supported by data on the correlation between vocabulary size and mutual exclusivity inferences (Lewis, et al., 2019). ${ }^{7}$

Further, in a direct test of the communicative word learning hypothesis, Frank and Goodman (2014) created a word learning situation in which three and four-year-olds were taught labels for features of objects. A target object (e.g., a dinosaur) had two features (e.g., a headdress

\footnotetext{
${ }^{7}$ We also note that the pragmatic view of mutual exclusivity is consistent with data showing that children (Horst \& Samuelson, 2008) and models (Smith, Goodman, \& Frank, 2013) both may sometimes make correct mutual exclusivity inferences without retaining the implied word meaning.
} 
and a bandana). The only disambiguating information came from the presence on a distractor object of one of the features (e.g., the headdress) but not the other. This asymmetry made the more unique feature (the bandana) a more informative label for the target object in the context. Consistent with the inferential model, both age groups were successful at inferring that the speaker was referring to the more unique, informative feature.

The work we have reviewed in this section largely tested how children use one form of pragmatic information in a word learning context. In addition to explaining these individual findings, our theoretical framework provides a way to think about how different forms of information can be integrated. In a recent study, we investigated how children and adults integrate common ground information with expectations about speaker informativity in a word learning context (Bohn, Tessler, Frank, 2019; Bohn, Tessler, Merrick \& Frank, in prep). We used a RSA model to generate a priori predictions about how information integration should proceed. These model predictions were closely aligned with the data and a model comparison suggested that word learning was best explained by a model that flexibly traded-off between the two information sources (common ground and speaker informativity) compared to models focusing only on one aspect or the other. This finding highlights the utility of the integrative, inferential framework presented here for explaining children's behavior across a wide range of word learning tasks.

\section{Pragmatics in children's communication and comprehension}

In the previous section we reviewed how children's language learning is supported by pragmatic inference. In the last part of our review, we turn to children's language use and comprehension, focusing on 3- to 6-year-old children who have sufficient vocabulary and 
grammatical ability to interpret more complex utterances reliably. Of course, pragmatic inferences based on social cues and context continues to help older children learn language. We see developmental change as a gradual shifting of emphasis, in which more often older children's more sophisticated linguistic abilities allow them to infer word meanings from the linguistic context (Gleitman, 1990), making them less dependent on pure pragmatic inference. During this period, however, pragmatics allows children to begin engaging subtle, context-specific use and interpretation of language, making their communication more efficient (and occasionally even polite).

\section{Conversation sensitive to social context}

As we have discussed above, the decision for what information to include in an utterance is partly determined by the common ground shared between interlocutors (H. H. Clark, 1996). Communication can be made more efficient (in the sense of reducing the cost of producing unnecessary utterances) by tuning what to say to what the partner already knows due to common ground. Although such prior expectations are likely in use in language learning substantially earlier, more sophisticated interactions of social context in conversation begin to be visible slightly later in productive language use.

By two years old, children can adjust the informativeness of their utterances to the knowledge state of their partner. For example, they name a hidden object and its location more often, and also produce more referential gestures, when their partner has not witnessed the hiding (O'Neil, 1996). Children of the same age also supplement their pointing gestures with linguistic information when pointing alone would be ambiguous (O’Neil \& Topolovec, 2001). Slightly older children are also more likely to use pronouns (which are usually shorter) instead of nouns 
to refer to an object if that object had been mentioned in the ongoing discourse (Matthews, Lieven, Theakston, \& Tomasello, 2006). In a peer context, three- and four-year-olds selectively mention facts when justifying a decision depending on whether their partner knows those facts already (Köymen, Mammen, \& Tomasello, 2016). And from five years onwards, children give general information about an object when the listener is unfamiliar with it but choose to mention more specific facts when the partner already knows about the object (Baer \& Friedman, 2018). In our theoretical framework, these adjustments are all reflected in the prior over messages and referents. Because the calculation of the utility of an utterance also takes in this prior, referents that have a high a priori probability have a high posterior probability even when a less informative utterance is used.

In addition to decisions about how much information to include in the utterance, pragmatic considerations also influence speakers' choice of words. Over the course of a conversation, specific expressions can be fine tuned to refer to specific objects or aspects of objects (Brennan \& Clark, 1996). The result of this tuning are called "referential pacts." These local conventions make communication efficient because they reduce the ambiguity of utterances. Such pacts can be produced in RSA-style models that simultaneously learn words and infer contextual interpretations (e.g., Hawkins, Frank, \& Goodman, 2017).

Children generate these partner-specific expectations about referential expressions at least from age three years and onwards (Matthews, Lieven, \& Tomasello, 2010). Children were slower to respond to a request when their partner violated a referential pact, but not when a different experimenter, with whom no pact was formed, used the same expression. Graham, Sedivy and Khu (2014) also provided evidence that referential pacts made children's 
communication faster: In an eye-tracking paradigm, 4 to 5-year-old children were faster to fixate on an object when a familiar speaker used a previously used expression compared to when a new speaker used the very same expression. Children between 4 and 6 years also form referential pacts in a peer context to differentiate between similar referents (e.g., they use the terms "horse" and "pony" to differentiate between two horses). Interestingly, they retain the partner-specific expressions even when they are technically no longer required because one of the competing referents has been removed (Köymen, Schmerse, Lieven, \& Tomasello, 2014).

\section{Pragmatic implicature}

Turning at last to the utterance itself, we consider the implicature phenomena that are core to most analyses of linguistic pragmatics. For example, when hearing "I ate some of the cookies", the listener may assume that the speaker did not eat all cookies - if they had eaten all, they should have used "all" instead of "some." From a purely semantic perspective, however, using "some" as part of a message that refers to all is not strictly false. The implicature follows from the assumption that speakers consider alternative utterances along an entailment scale ("all" entailing "some" in this case). Hence these inferences are referred to by the term "scalar implicature."

In light of the work we have reviewed so far, which we took to show that children engage in context-sensitive inferential communication from 1 year onwards, the findings from this strand of research present a puzzle. A number of studies have found that children of 5 years and even older struggle to compute implicatures, especially under time constraints (Noveck, 2001, Huang \& Snedeker, 2009). How can these failures be reconciled with the evidence reviewed above that children of even younger ages are so good at pragmatic inferences more broadly? 
The apparent contradiction between early competence and later failure can be resolved by looking at the facilitating conditions under which younger children succeed (see Papafragou \& Skordos, 2016 for a summary). For example, Skordos \& Papafragou (2016) showed that increasing the availability of the stronger alternative ("all" in the example above) improved 5-year-olds' performance; and Horowitz, Schneider and Frank (2018) showed that children who succeeded in making scalar implicatures were those who best knew all the quantificational alternatives. This pattern of data is consistent with our inferential framework, in which the utility of an utterance (given a message) depends on the specific alternatives being considered (see e.g., Peloquin \& Frank, 2016 for an analysis). This interpretation suggests that children do not necessarily struggle with inference per se, but with generating the alternatives that are the basis for it (Barner, Brooks, \& Bale, 2011).

Further evidence consistent with the hypothesis that children's pragmatic abilities are intact, despite their struggle with specific linguistic materials, comes from "ad hoc" (contextual, rather than linguistic) implicatures. Stiller, Goodman and Frank (2015) used a simplified design in which the alternatives for an implicature were perceptually available features of a scene and found success at 3 years of age, substantially earlier than the earliest evidence for implicature with quantifiers. Further, the performance of even younger children in this simplified task is heavily influenced by perceptual properties of the presented alternatives, suggesting again that inference per se is not the problem but the properties and availability of the alternatives it is based on (Yoon and Frank, in press). In sum, pragmatic inference critically relies on experience with the conventional use of expressions; without a full lexicon, specific inferences can be impossible to generate. 


\section{Using pragmatics to navigate the (social) world}

In addition to resolving ambiguities, pragmatic reasoning can allow children to learn from others. An adjacent body of work on non-linguistic social learning phenomena suggests that 3 to 5-year-old children are remarkably good at learning from others' communicative actions (e.g., Jara-Ettinger et al., 2016; Bonawitz et al., 2011). This social learning can also be accomplished using linguistic inferences. For example, Horowitz and Frank (2016) taught children the name of a novel object and also commented on its property (e.g. "This is a small fep"). The contrastive use of the adjective implied that prototypical members of the category look different from the exemplar (they are bigger). When 3 to 5-year-olds were asked to identify such a prototype, they chose the object that differed from the exemplar in the property the speaker previously commented on.

Finally, pragmatic language provides a way for navigating the social world. From that perspective, ambiguous or inefficient language reflects a conflict of multiple social goals the speaker wants to achieve. A case in point is polite language. Polite language feature words that have no informational value and requests are often framed as questions even though they have an imperative core. For example, "Can you please open the window?" is a polite way of saying "open the window!". In addition to the goal of transmitting information (I want you to open the window), the speaker considers how the message would affect the listener's self-image or face (Brown \& Levinson, 1987). An imperative request might be perceived as a threat to the listener's freedom from imposition and cause them to leave the interaction. Because communication is a cooperative endeavor, it requires the active participation of all interlocutors to achieve the joint 
goal of mutual understanding. By using polite language, the speaker signals benign intend and a willingness to cooperate (H. H. Clark, 1996).

From 2.5 years onwards, and increasingly with age, children start to use politeness markers such as "please” (Bates \& Silvern, 1977; Read \& Cherry, 1978). However, production of politeness markers alone does not show an understanding of the social function of polite speech, but could be a rule children follow to get what they want (Gleason, Perlmann, \& Greif, 1984). Yoon and Frank (2019) therefore asked children at 2, 3 and 4 years of age whether speakers who use markers like "please" or "can you ..." were more polite or more likely to achieve their goal. From 3 years onwards, children judged speakers who say "please" as more polite and from 4 onwards they assumed that a speaker using polite language would be more likely to get what they want. Though this work is in its early stages, such social inferences appear to be described well using a slight extension to the RSA framework (Yoon et al., 2018).

\section{Developmental questions about pragmatic reasoning}

With the help of the framework described above, we are now able to pose developmental questions about continuity and change much more effectively. (This is a specific instance of a general phenomenon - developmental theorizing is facilitated immensely by strong theories of the end state; cf. Tomasello, 2000; Leslie et al., 1998). In particular, we can ask about developmental change in each posited construct in our framework - linguistic knowledge/the lexicon, Gricean reasoning, and common ground - as well as about whether the broader framework applies equally to children and adults.

The developmental scope we are examining is quite broad, beginning just before the first birthday and ending - in our examination, though certainly not in the life of a child - around the 
beginning of formal education at ages 5 to 6 . In light of the literature reviewed above, we believe that the evidence is in favor of continuity, rather than separate developmental trajectories of language learning and social cognition. That is, from relatively early in development - perhaps 6-9 months - infants' view of language is communicative in nature (Waxman \& Gelman, 2009). The substance of this claim in our framework is that the basic constructs posited by our framework - including pragmatic inference, common ground, and the lexicon - are all in place by this early time and being used interactively with one another in sophisticated ways. As we reviewed, this conceptualization stands in contrast with other views that have posited developmental shifts in how infants view early language. In particular, we do not believe that the evidence supports a shift from an earlier associative conceptualization of language - in which language is initially represented by stimulus-stimulus associations (e.g., Sloutsky 2017; Hollich, Hirsh-Pasek, \& Golinkoff, 2000).

While we endorse the hypothesis that infants in the second half of their first year share the assumption that language is communicative, we remain agnostic about how early this continuity can be found. One possibility is that there is some innate adaptation for communication such that even early in infancy language is processed inferentially (e.g., Hespos, Ferry, \& Waxman, 2010), though evidence is relatively scant at this very young age. Another possibility, however, is that the communicative basis of language is discovered by infants through their observation of the social world. Although 6-month-olds may know very little about 
the specifics of language, an intriguing possibility is that they have already induced its broad function in manipulating human behavior. ${ }^{8}$

Regardless of the very early origins of communication, the broad developmental continuity that we have described here is often masked in children's observed behavior due to the truly transformational developmental changes that occur contemporaneously with the emergence of early language. Language itself is emerging - that is, children are learning the meanings of words and the ways they can be combined compositionally. Within the broad time period we considered, there is tremendous change in linguistic knowledge, from its very beginnings during the first year (Bergelson \& Swingley, 2012) through its ramification and exponential growth over the subsequent years (Fenson et al., 1994). Trivially, without the ability to retrieve word meanings accurately and to interpret their composition, inferences that go beyond literal meaning are impossible. And language-processing speed changes dramatically during the early years of language learning (Fernald et al., 1998; Fernald et al., 2006); thus, even if young children can interpret an utterance, they may not be able to do so with enough time to make a sophisticated inference (see e.g., Huang \& Snedeker, 2009).

Further, a variety of social cognition skills adjacent to communication are being practiced extensively during early development. For example, infants are becoming more expert at action prediction (e.g. Cannon \& Woodward, 2012; Falck-Ytter, Gredebäck, \& von Hofsten, 2006; Kanakogi \& Itakura, 2011), gaze following (Moore, 2008) and processing directional actions as referential (Daum \& Gredebäck, 2011; Gredebäck, Melinder, \& Daum, 2010). The ability to

\footnotetext{
${ }^{8}$ Such induction of framework hypotheses in the absence of specific supporting knowledge is known as the "blessing of abstraction" and has been posited for other framework theories like the theory of causality (Goodman et al., 2010).
} 
compute other's perspective (Sodian, Thoermer, Metz, 2007) and track what they experience also develops substantially after the first birthday (Moll \& Tomasello, 2007). Furthermore, children are getting better at explicitly reasoning about the relationship between beliefs, desires, and actions (Perner \& Wimmer, 1985; Wellman, 2014) as well as about other's motives for action more broadly (Jara-Ettinger, et al., 2016). ${ }^{9}$

Finally, a wide variety of other abilities are themselves developing during this time period. During precisely the period in which we observe changes in children's communication abilities, they are also undergoing massive developmental changes in domain-general abilities like working memory (Camos, \& Barrouillet, 2018; Reznick, Morrow, Goldman, \& Snyder, 2004), executive function (Diamond, 2013; McGuigan, \& Núñez, 2006), and general speed of processing (Kail, 1991). The involvement of these abilities in early language processing is at present unknown, but an important goal for future research is understanding the extent to which developmental changes in pragmatic inference relate to these general developmental trends (cf. Yoon \& Frank, in press).

\section{Conclusion}

We presented pragmatic inference as a pervasive theme in children's language, linking early communication based on social cues with word learning and language use. Further, we used the RSA model as a theoretical beginning from which to argue for developmental continuity - the thesis that by 6-9 months, all of the ingredients of mature pragmatic inference are present. Developmental changes after this point are then attributed to the successive refinement of

\footnotetext{
${ }^{9}$ Note that we are deliberately agnostic about whether all pragmatic reasoning requires a fully-fledged theory of mind in the sense of Premack \& Woodruff (1978). While there is a wide variety of (conflicting) evidence on the question of whether infants can represent others' mental states (e.g., Onishi \& Baillargeon, 2005; Southgate, Senju, \& Csibra, 2007; cf. Kulke \& Rakoczy, 2018), much of this evidence bears on the representation specifically of false beliefs. False belief understanding is not required for the communicative inferences we review here.
} 
children's abilities - including their linguistic knowledge and their general processing abilities. We hope that this framework helps researchers in the area see the commonalities between the wide range of tasks and terminologies that are used to study early language from a "pragmatic" perspective.

Perhaps the most severe limitation of this review and the theoretical framework it advocates for is its basis in data collected in western, affluent, and urban settings. This systematic bias is widespread in (developmental) psychology and generally limits the scope of theorizing (Henrich, Heine, \& Norenzayan, 2010; Nielsen, Haun, Kärtner, Legare, 2017). While we are optimistic that the communicative inference view would hold in non-western settings, much research is needed to test if this is actually the case. While the anthropological literature has hinted at differences in which and how pragmatic inferences are computed across cultures (Harris, 1996; Le Guen, 2018), developmental work on how culture influences early communication or linguistic pragmatics is still rare (cf. Fortier, Kellier, Flecha, \& Frank, 2018; Liszkowski, et al., 2012; Salomo \& Liszkowski, 2013; Zhao, Zhou, Ren, \& Frank, in prep). In principle, the modeling framework we presented offers a straightforward way to incorporate cross-cultural (and also interindividual) variation by assuming a universal model structure with a differential weighing of different information sources. For example, it might be that listeners all across the world consider gaze cues and linguistic information when interpreting an utterance but the relative importance of the two differs across cultures. More broadly, we think that the use of explicit computational theories offers new possibilities to incorporate cross-cultural variation in unified theoretical frameworks. 
We are continually astonished by the flexibility and efficiency of human communication. In the right circumstances, a seemingly-ambiguous message can lead to a rich interpretation through a social inference about the goals of the speaker. The pragmatic viewpoint provides a way to explain this powerful ability. We have argued here that this viewpoint can be applied productively not just to apparent instances of pragmatic implicature in childhood but also to the communicative abilities of infants. We hope that this perspective inspires further experiments elucidating both the origins of these abilities and their variability across cultures. 


\section{References}

Adamson, L. B., Bakeman, R., \& Deckner, D. F. (2004). The development of symbol-infused joint engagement. Child Development, 75(4), 1171-1187.

Akhtar, N. (2002). Relevance and early word learning. Journal of Child Language, 29(3), $677-686$.

Akhtar, N., Carpenter, M., \& Tomasello, M. (1996). The role of discourse novelty in early word learning. Child Development, 67(2), 635-645.

Baer, C., \& Friedman, O. (2018). Fitting the message to the listener: Children selectively mention general and specific facts. Child Development, 89(2), 461-475.

Baldwin, D. A. (1993). Early referential understanding: Infants' ability to recognize referential acts for what they are. Developmental Psychology, 29(5), 832-843.

Baldwin, D. A., Markman, E. M., Bill, B., Desjardins, R. N., Irwin, J. M., \& Tidball, G. (1996). Infants' reliance on a social criterion for establishing word-object relations. Child Development, 67(6), 3135-3153.

Barner, D., Brooks, N., \& Bale, A. (2011). Accessing the unsaid: The role of scalar alternatives in children's pragmatic inference. Cognition, 118(1), 84-93.

Bates, E. (1976). Language and context: The acquisition of pragmatics. New York: Academic Press.

Bates, E., \& Silvern, L. (1977). Social adjustment and politeness in preschoolers. Journal of Communication, 27, 104-111. 
Behne, T., Carpenter, M., \& Tomasello, M. (2005). One-year-olds comprehend the communicative intentions behind gestures in a hiding game. Developmental Science, $8(6), 492-499$.

Bergelson, E., \& Aslin, R. N. (2017). Nature and origins of the lexicon in 6-mo-olds. Proceedings of the National Academy of Sciences, 114(49), 12916-12921.

Bergelson, E., \& Swingley, D. (2012). At 6-9 months, human infants know the meanings of many common nouns. Proceedings of the National Academy of Sciences, 109(9), $3253-3258$.

Bergen, L., Levy, R., \& Goodman, N. (2016). Pragmatic reasoning through semantic inference. Semantics and Pragmatics, 9.

Bloom, P. (2002). How children learn the meanings of words. Cambridge: MIT Press.

Bohn, M., \& Köymen, B. (2018). Common ground and development. Child Development Perspectives, 12(2), 104-108.

Bohn, M., Call, J., \& Tomasello, M. (2015). Communication about absent entities in great apes and human infants. Cognition, 145, 63-72.

https://doi.org/10.1016/j.cognition.2015.08.009

Bohn, M., Call, J., \& Tomasello, M. (2016). Comprehension of iconic gestures by chimpanzees and human children. Journal of Experimental Child Psychology, 142, 1-17. 
Bohn, M., Call, J., \& Tomasello, M. (2019). Natural reference: A phylo-and ontogenetic perspective on the comprehension of iconic gestures and vocalizations. Developmental Science, 22(2), e12757.

Bohn, M., Tessler, M. H., \& Frank, M. C. (2019). Integrating common ground and informativeness in pragmatic word learning. Proceedings of the 41st Annual Conference of the Cognitive Science Society.

Bohn, M., Tessler, M. H., Merrick, M. and, \& Frank, M. C. (in prep). Integrating utterance and common ground information during pragmatic word learning across development.

Bohn, M., Zimmermann, L., Call, J., \& Tomasello, M. (2018). The social-cognitive basis of infants' reference to absent entities. Cognition, 177, 41-48.

Bonawitz, E., Shafto, P., Gweon, H., Goodman, N. D., Spelke, E., \& Schulz, L. (2011). The double-edged sword of pedagogy: Instruction limits spontaneous exploration and discovery. Cognition, 120(3), 322-330.

Booth, A. E., \& Waxman, S. R. (2009). A horse of a different color: Specifying with precision infants' mappings of novel nouns and adjectives. Child Development, 80(1), 15-22.

Bottema-Beutel, K. (2016). Associations between joint attention and language in autism spectrum disorder and typical development: A systematic review and meta-regression analysis. Autism Research, 9(10), 1021-1035.

Brennan, S. E., \& Clark, H. H. (1996). Conceptual pacts and lexical choice in conversation. Journal of Experimental Psychology: Learning, Memory, and Cognition, 22(6), 1482. 
Brooks, R., \& Meltzoff, A. N. (2005). The development of gaze following and its relation to language. Developmental Science, 8(6), 535-543.

Brooks, R., \& Meltzoff, A. N. (2008). Infant gaze following and pointing predict accelerated vocabulary growth through two years of age: A longitudinal, growth curve modeling study. Journal of Child Language, 35(1), 207-220.

Brown, P., \& Levinson, S. C. (1987). Politeness: Some universals in language usage. Cambridge: Cambridge University Press.

Bühler, K. (1934). Sprachtheorie. Oxford: Fischer.

Camos, V., \& Barrouillet, P. (2018). Working memory in development. London: Routledge.

Cannon, E. N., \& Woodward, A. L. (2012). Infants generate goal-based action predictions. Developmental Science, 15(2), 292-298.

Carey, S., \& Bartlett, E. (1978). Acquiring a single new word. Proceedings of the Stanford Child Language Conference, 15, 17-29.

Carpenter, M., Nagell, K., \& Tomasello, M. (1998). Social cognition, joint attention, and communicative competence from 9 to 15 months of age. Monographs of the Society for Research in Child Development, 63(4), i-143.

Chierchia, G. (2004). Scalar implicatures, polarity phenomena and the syntax/pragmatics interface. In A. Belletti (Ed.), Structures and Beyond (pp. 39-103). Oxford: Oxford University Press. 
Childers, J. B., Vaughan, J., \& Burquest, D. A. (2007). Joint attention and word learning in ngas-speaking toddlers in nigeria. Journal of Child Language, 34(2), 199-225.

Clark, E. V. (1988). On the logic of contrast. Journal of Child Language, 15(2), 317-335.

Clark, E. V. (2009). First language acquisition. Cambridge: Cambridge University Press.

Clark, E. V. (2015). Common ground. In B. MacWhinney \& W. O’Grady (Eds.), The handbook of language emergence (Vol. 87, pp. 328-353). John Wiley \& Sons.

Clark, E. V., \& Amaral, P. M. (2010). Children build on pragmatic information in language acquisition. Language and Linguistics Compass, 4(7), 445-457.

Clark, E. V., \& Grossman, J. B. (1998). Pragmatic directions and children's word learning. Journal of Child Language, 25(1), 1-18.

Clark, H. H. (1996). Using language. Cambridge : Cambridge University Press.

Colonnesi, C., Stams, G. J. J., Koster, I., \& Noom, M. J. (2010). The relation between pointing and language development: A meta-analysis. Developmental Review, 30(4), 352-366.

Daum, M. M., \& Gredebäck, G. (2011). The development of grasping comprehension in infancy: Covert shifts of attention caused by referential actions. Experimental Brain Research, 208(2), 297-307.

Dewar, K., \& Xu, F. (2007). Do 9-month-old infants expect distinct words to refer to kinds? Developmental Psychology, 43(5), 1227-1238.

Diamond, A. (2013). Executive functions. Annual Review of Psychology, 64, 135-168. 
Diesendruck, G., Markson, L., Akhtar, N., \& Reudor, A. (2004). Two-year-olds'sensitivity to speakers' intent: An alternative account of samuelson and smith. Developmental Science, $7(1), 33-41$.

Donnellan, E., Bannard, C., McGillion, M. L., Slocombe, K. E., \& Matthews, D. (2019). Infants' intentionally communicative vocalisations elicit responses from caregivers and are the best predictors of the transition to language: A longitudinal investigation of infants' vocalisations, gestures, and word production. Developmental Science, e12843.

Dunham, P. J., Dunham, F., \& Curwin, A. (1993). Joint-attentional states and lexical acquisition at 18 months. Developmental Psychology, 29(5), 827-831.

Egyed, K., Király, I., \& Gergely, G. (2013). Communicating shared knowledge in infancy. Psychological Science, 24(7), 1348-1353.

Falck-Ytter, T., Gredebäck, G., \& Hofsten, C. von. (2006). Infants predict other people's action goals. Nature Neuroscience, 9(7), 878.

Fenson, L., Dale, P. S., Reznick, J. S., Bates, E., Thal, D. J., \& Pethick, S. J. (1994). Variability in early communicative development. Monographs of the Society for Research in Child Development, 59(5), 1-185.

Ferguson, B., \& Lew-Williams, C. (2016). Communicative signals support abstract rule learning by 7-month-old infants. Scientific Reports, 6, 25434.

Ferguson, B., \& Waxman, S. R. (2016). What the [beep]? Six-month-olds link novel communicative signals to meaning. Cognition, 146, 185-189. 
Fernald, A., Perfors, A., \& Marchman, V. A. (2006). Picking up speed in understanding: Speech processing efficiency and vocabulary growth across the 2nd year. Developmental Psychology, 42(1), 98-116.

Fernald, A., Pinto, J. P., Swingley, D., Weinbergy, A., \& McRoberts, G. W. (1998). Rapid gains in speed of verbal processing by infants in the 2nd year. Psychological Science, 9(3), 228-231.

Ferry, A. L., Hespos, S. J., \& Waxman, S. R. (2010). Categorization in 3-and 4-month-old infants: An advantage of words over tones. Child Development, 81(2), 472-479.

Fortier, M., Kellier, D., Flecha, M. F., \& Frank, M. C. (2018). Ad-hoc pragmatic implicatures among shipibo-konibo children in the peruvian amazon. Psyarxiv.com/X7ad9. https://doi.org/10.31234/osf.io/x 7ad9

Frank, M. C., \& Goodman, N. D. (2012). Predicting pragmatic reasoning in language games. Science, 336(6084), 998-998.

Frank, M. C., \& Goodman, N. D. (2014). Inferring word meanings by assuming that speakers are informative. Cognitive Psychology, 75, 80-96.

Frank, M. C., Braginsky, M., Yurovsky, D., \& Marchman, V. A. (2017). Wordbank: An open repository for developmental vocabulary data. Journal of Child Language, 44(3), 677-694.

Frank, M. C., Braginsky, M., Yurovsky, D., \& Marchman, V. A. (in prep). Variability and consistency in early language learning: The wordbank project. Cambridge: MIT Press. 
Frank, M. C., Goodman, N. D., \& Tenenbaum, J. B. (2009). Using speakers' referential intentions to model early cross-situational word learning. Psychological Science, 20(5), $578-585$.

Ganea, P. A. (2005). Contextual factors affect absent reference comprehension in 14-month-olds. Child Development, 76(5), 989-998.

Ganea, P. A., \& Saylor, M. M. (2013). Talking about the near and dear: Infants' comprehension of displaced speech. Developmental Psychology, 49(7), 1299-1307. https://doi.org/10.1037/a0030086

Gibson, E., Piantadosi, S. T., Brink, K., Bergen, L., Lim, E., \& Saxe, R. (2013). A noisy-channel account of crosslinguistic word-order variation. Psychological Science, 24(7), 1079-1088.

Gleason, J. B., Perlmann, R. Y., \& Greif, E. B. (1984). What's the magic word: Learning language through politeness routines. Discourse Processes, 7(4), 493-502.

Gleitman, L. (1990). The structural sources of verb meanings. Language Acquisition, 1(1), 3-55.

Goodman, N. D., \& Frank, M. C. (2016). Pragmatic language interpretation as probabilistic inference. Trends in Cognitive Sciences, 20(11), 818-829.

Goodman, N. D., \& Stuhlmüller, A. (2013). Knowledge and implicature: Modeling language understanding as social cognition. Topics in Cognitive Science, 5(1), 173-184.

Graham, S. A., Sedivy, J., \& Khu, M. (2014). That's not what you said earlier: Preschoolers expect partners to be referentially consistent. Journal of Child Language, 41(1), 34-50. 
Grassmann, S., \& Tomasello, M. (2010). Young children follow pointing over words in interpreting acts of reference. Developmental Science, 13(1), 252-263.

Gredebäck, G., Astor, K., \& Fawcett, C. (2018). Gaze following is not dependent on ostensive cues: A critical test of natural pedagogy. Child Development, 89(6), 2091-2098.

Gredebäck, G., Melinder, A., \& Daum, M. M. (2010). The development and neural basis of pointing comprehension. Social Neuroscience, 5(5-6), 441-450.

Grice, H. P. (1975). Logic and conversation. In P. Cole \& J. L. Morgan (Eds.), Syntax and semantics: Vol. 3: Speech acts (pp. 41-58). New York.

Grueneisen, S., Wyman, E., \& Tomasello, M. (2015). "I know you don’t know i know...” children use second-order false-belief reasoning for peer coordination. Child Development, 86(1), 287-293.

Halberda, J. (2003). The development of a word-learning strategy. Cognition, 87(1), B23-B34.

Hare, B., Brown, M., Williamson, C., \& Tomasello, M. (2002). The domestication of social cognition in dogs. Science, 298(5598), 1634-1636.

Hawkins, R. X., Frank, M. C., \& Goodman, N. D. (2017). Convention-formation in iterated reference games. Proceedings of the 39th Annual Conference of the Cognitive Science Society.

Henrich, J., Heine, S. J., \& Norenzayan, A. (2010). The weirdest people in the world? Behavioral and Brain Sciences, 33(2-3), 61-83. 
Hernik, M., \& Broesch, T. (2018). Infant gaze following depends on communicative signals: An eye-tracking study of 5-to 7-month-olds in vanuatu. Developmental Science, e12779.

Hirotani, M., Stets, M., Striano, T., \& Friederici, A. D. (2009). Joint attention helps infants learn new words: Event-related potential evidence. Neuroreport, 20(6), 600-605.

Hollich, G. J., Hirsh-Pasek, K., \& Golinkoff, R. M. (2000). Breaking the language barrier: An emergentist coalition model for the origins of word learning. Monographs of the Society for Research in Child Development, 65(3), i-135.

Horowitz, A. C., \& Frank, M. C. (2015). Young children's developing sensitivity to discourse continuity as a cue for inferring reference. Journal of Experimental Child Psychology, $129,84-97$.

Horowitz, A. C., \& Frank, M. C. (2016). Children's pragmatic inferences as a route for learning about the world. Child Development, 87(3), 807-819.

Horowitz, A. C., Schneider, R. M., \& Frank, M. C. (2018). The trouble with quantifiers: Exploring children's deficits in scalar implicature. Child Development, 89(6), e572-e593.

Horst, J. S., \& Samuelson, L. K. (2008). Fast mapping but poor retention by 24-month-old infants. Infancy, 13(2), 128-157.

Huang, Y. T., \& Snedeker, J. (2009). Online interpretation of scalar quantifiers: Insight into the semantics-pragmatics interface. Cognitive Psychology, 58(3), 376-415. 
Jara-Ettinger, J., Gweon, H., Schulz, L. E., \& Tenenbaum, J. B. (2016). The naïve utility calculus: Computational principles underlying commonsense psychology. Trends in Cognitive Sciences, 20(8), 589-604.

Jäger, G. (2012). Game theory in semantics and pragmatics. Semantics: An International Handbook of Natural Language Meaning, 3, 2487-2425.

Kail, R. (1991). Processing time declines exponentially during childhood and adolescence. Developmental Psychology, 27(2), 259-266.

Kamhi, A. G. (1986). The elusive first word: The importance of the naming insight for the development of referential speech. Journal of Child Language, 13(1), 155-161.

Kanakogi, Y., \& Itakura, S. (2011). Developmental correspondence between action prediction and motor ability in early infancy. Nature Communications, 2, 341 .

Kano, F., \& Call, J. (2014). Cross-species variation in gaze following and conspecific preference among great apes, human infants and adults. Animal Behaviour, 91, 137-150.

Kao, J. T., Wu, J. Y., Bergen, L., \& Goodman, N. D. (2014). Nonliteral understanding of number words. Proceedings of the National Academy of Sciences, 111(33), 12002-12007.

Katsos, N., \& Cummins, C. (2010). Pragmatics: From theory to experiment and back again. Language and Linguistics Compass, 4(5), 282-295.

Király, I., Oláh, K., Csibra, G., \& Kovács, Á. M. (2018). Retrospective attribution of false beliefs in 3-year-old children. Proceedings of the National Academy of Sciences, 115(45), 11477-11482. 
Köymen, B., Mammen, M., \& Tomasello, M. (2016). Preschoolers use common ground in their justificatory reasoning with peers. Developmental Psychology, 52(3), 423-429.

Köymen, B., Schmerse, D., Lieven, E., \& Tomasello, M. (2014). Young children create partner-specific referential pacts with peers. Developmental Psychology, 50(10), 2334-2342.

Kulke, L., \& Rakoczy, H. (2018). Implicit theory of mind-An overview of current replications and non-replications. Data in Brief, 16, 101-104.

Lassiter, D., \& Goodman, N. D. (2017). Adjectival vagueness in a bayesian model of interpretation. Synthese, 194(10), 3801-3836.

Leslie, A. M., Xu, F., Tremoulet, P. D., \& Scholl, B. J. (1998). Indexing and the object concept: Developing 'what' and 'where' systems. Trends in Cognitive Sciences, 2(1), 10-18.

Levelt, W. J. (2014). A history of psycholinguistics: The pre-chomskyan era. Oxford: Oxford University Press.

Levinson, S. C. (2000). Presumptive meanings: The theory of generalized conversational implicature. Cambridge : MIT press.

Lewis, M., Cristiano, V., Lake, B. M., Kwan, T., \& Frank, M. C. (2019). The role of developmental change and linguistic experience in the mutual exclusivity effect. Psyarxiv.com/Wsx3a. https://doi.org/10.31234/osf.io/wsx3a

Liszkowski, U., Brown, P., Callaghan, T., Takada, A., \& De Vos, C. (2012). A prelinguistic gestural universal of human communication. Cognitive Science, 36(4), 698-713. 
Liszkowski, U., Carpenter, M., \& Tomasello, M. (2008). Twelve-month-olds communicate helpfully and appropriately for knowledgeable and ignorant partners. Cognition, 108(3), 732-739.

Liszkowski, U., Schäfer, M., Carpenter, M., \& Tomasello, M. (2009). Prelinguistic infants, but not chimpanzees, communicate about absent entities. Psychological Science, 20(5), 654-660. https://doi.org/10.1111/j.1467-9280.2009.02346.x

Lüke, C., Grimminger, A., Rohlfing, K. J., Liszkowski, U., \& Ritterfeld, U. (2017). In infants' hands: Identification of preverbal infants at risk for primary language delay. Child Development, 88(2), 484-492.

Markman, E. M., \& Wachtel, G. F. (1988). Children's use of mutual exclusivity to constrain the meanings of words. Cognitive Psychology, 20(2), 121-157.

Markman, E. M., Wasow, J. L., \& Hansen, M. B. (2003). Use of the mutual exclusivity assumption by young word learners. Cognitive Psychology, 47(3), 241-275.

Marr, D. (1982). Vision: A computational investigation into the human representation and processing of visual information. San Francisco: WH Freeman.

Martin, A., Onishi, K. H., \& Vouloumanos, A. (2012). Understanding the abstract role of speech in communication at 12 months. Cognition, 123(1), 50-60.

Matthews, D., Lieven, E., \& Tomasello, M. (2010). What's in a manner of speaking? Children's sensitivity to partner-specific referential precedents. Developmental Psychology, 46(4), 749-760. 
Matthews, D., Lieven, E., Theakston, A., \& Tomasello, M. (2006). The effect of perceptual availability and prior discourse on young children's use of referring expressions. Applied Psycholinguistics, 27(3), 403-422.

McGuigan, N., \& Núñez, M. (2006). Executive functioning by 18-24-month-old children: Effects of inhibition, working memory demands and narrative in a novel detour-reaching task. Infant and Child Development, 15(5), 519-542.

McMurray, B., Horst, J. S., \& Samuelson, L. K. (2012). Word learning emerges from the interaction of online referent selection and slow associative learning. Psychological Review, 119(4), 831-877.

Moll, H., \& Tomasello, M. (2007). How 14-and 18-month-olds know what others have experienced. Developmental Psychology, 43(2), 309-317.

Moore, C. (2008). The development of gaze following. Child Development Perspectives, 2(2), 66-70.

Moore, C., Dailey, S., Garrison, H., Amatuni, A., \& Bergelson, E. (2019). Point, walk, talk: Links between three early milestones, from observation and parental report. Developmental Psychology.

Moore, R., Mueller, B., Kaminski, J., \& Tomasello, M. (2015). Two-year-old children but not domestic dogs understand communicative intentions without language, gestures, or gaze. Developmental Science, 18(2), 232-242. 
Mundy, P., Block, J., Delgado, C., Pomares, Y., Van Hecke, A. V., \& Parlade, M. V. (2007). Individual differences and the development of joint attention in infancy. Child Development, 78(3), 938-954.

Nadig, A. S., \& Sedivy, J. C. (2002). Evidence of perspective-taking constraints in children's on-line reference resolution. Psychological Science, 13(4), 329-336.

Nelson, K. (1973). Structure and strategy in learning to talk. Monographs of the Society for Research in Child Development, 38(1), 1-135.

Nielsen, M., Haun, D., Kärtner, J., \& Legare, C. H. (2017). The persistent sampling bias in developmental psychology: A call to action. Journal of Experimental Child Psychology, $162,31-38$.

Nilsen, E. S., \& Graham, S. A. (2009). The relations between children's communicative perspective-taking and executive functioning. Cognitive Psychology, 58(2), 220-249.

Noveck, I. A. (2001). When children are more logical than adults: Experimental investigations of scalar implicature. Cognition, 78(2), 165-188.

Noveck, I. A., \& Sperber, D. (2004). Experimental pragmatics. Basingstoke: Palgrave Macmillan.

Onishi, K. H., \& Baillargeon, R. (2005). Do 15-month-old infants understand false beliefs? Science, 308(5719), 255-258. 
Osina, M. A., Saylor, M. M., \& Ganea, P. A. (2014). Object locations, identity and absent reference understanding at 12 months. Infancy, 19(1), 65-81. https://doi.org/10.1111/infa.12031

Osina, M. A., Saylor, M. M., \& Ganea, P. A. (2017). Out of reach, out of mind? Infants' comprehension of references to hidden inaccessible objects. Child Development, $88(5)$, 1572-1580. https://doi.org/10.1111/cdev.12656

O’Neill, D. K. (1996). Two-year-old children's sensitivity to a parent's knowledge state when making requests. Child Development, 67(2), 659-677.

O’Neill, D. K., \& Topolovec, J. C. (2001). Two-year-old children's sensitivity to the referential (in) efficacy of their own pointing gestures. Journal of Child Language, 28(1), 1-28.

Papafragou, A., \& Musolino, J. (2003). Scalar implicatures: Experiments at the semantics-pragmatics interface. Cognition, 86(3), 253-282.

Papafragou, A., \& Skordos, D. (2016). Scalar implicature. In J. Lidz, W. Snyder, \& J. Pater (Eds.), The Oxford Hanbook of Developmental Linguistics (pp. 611-632). Oxford University Press.

Peloquin, B., \& Frank, M. C. (2016). Determining the alternatives for scalar implicature. Proceedings of the 38th Annual Conference of the Cognitive Science Society.

Perner, J., \& Wimmer, H. (1985). "John thinks that mary thinks that..." attribution of second-order beliefs by 5-to 10-year-old children. Journal of Experimental Child Psychology, 39(3), 437-471. 
Potts, C., Lassiter, D., Levy, R., \& Frank, M. C. (2016). Embedded implicatures as pragmatic inferences under compositional lexical uncertainty. Journal of Semantics, 33(4), 755-802.

Premack, D., \& Woodruff, G. (1978). Does the chimpanzee have a theory of mind? Behavioral and Brain Sciences, 1(4), 515-526.

Read, B. K., \& Cherry, L. J. (1978). Preschool children's production of directive forms. Discourse Processes, 1(3), 233-245.

Regier, T. (2003). Emergent constraints on word-learning: A computational perspective. Trends in Cognitive Sciences, 7(6), 263-268.

Reznick, J. S., Morrow, J. D., Goldman, B. D., \& Snyder, J. (2004). The onset of working memory in infants. Infancy, 6(1), 145-154.

Rowe, M. L., \& Goldin-Meadow, S. (2009). Differences in early gesture explain ses disparities in child vocabulary size at school entry. Science, 323(5916), 951-953.

Salomo, D., \& Liszkowski, U. (2013). Sociocultural settings influence the emergence of prelinguistic deictic gestures. Child Development, 84(4), 1296-1307.

Saylor, M. M., Ganea, P. A., \& Vázquez, M. D. (2011). What's mine is mine: Twelve-month-olds use possessive pronouns to identify referents. Developmental Science, 14(4), 859-864.

Saylor, M. M., Sabbagh, M. A., Fortuna, A., \& Troseth, G. (2009). Preschoolers use speakers’ preferences to learn words. Cognitive Development, 24(2), 125-132. 
Scofield, J., \& Behrend, D. A. (2011). Clarifying the role of joint attention in early word learning. First Language, 31(3), 326-341.

Senju, A., \& Csibra, G. (2008). Gaze following in human infants depends on communicative signals. Current Biology, 18(9), 668-671.

Shafto, P., Goodman, N. D., \& Frank, M. C. (2012). Learning from others: The consequences of psychological reasoning for human learning. Perspectives on Psychological Science, 7(4), 341-351.

Skordos, D., \& Papafragou, A. (2016). Children's derivation of scalar implicatures: Alternatives and relevance. Cognition, 153, 6-18.

Sloutsky, V. M., Lo, Y.-F., \& Fisher, A. V. (2001). How much does a shared name make things similar? Linguistic labels, similarity, and the development of inductive inference. Child Development, 72(6), 1695-1709.

Sloutsky, V. M., Yim, H., Yao, X., \& Dennis, S. (2017). An associative account of the development of word learning. Cognitive Psychology, 97, 1-30.

Smith, L., \& Yu, C. (2008). Infants rapidly learn word-referent mappings via cross-situational statistics. Cognition, 106(3), 1558-1568.

Smith, N. J., Goodman, N., \& Frank, M. (2013). Learning and using language via recursive pragmatic reasoning about other agents, 3039-3047.

Sodian, B., Thoermer, C., \& Metz, U. (2007). Now i see it but you don't: 14-month-olds can represent another person's visual perspective. Developmental Science, 10(2), 199-204. 
Southgate, V., Chevallier, C., \& Csibra, G. (2010). Seventeen-month-olds appeal to false beliefs to interpret others' referential communication. Developmental Science, 13(6), 907-912.

Southgate, V., Senju, A., \& Csibra, G. (2007). Action anticipation through attribution of false belief by 2-year-olds. Psychological Science, 18(7), 587-592.

Sperber, D., \& Wilson, D. (2001). Relevance: Communication and cognition (2nd ed.). Cambridge : Blackwell Publishers.

Srinivasan, M., Foushee, R., Bartnof, A., \& Barner, D. (2019). Linguistic conventionality and the role of epistemic reasoning in children's mutual exclusivity inferences. Cognition, 189, $193-208$.

Stiller, A. J., Goodman, N. D., \& Frank, M. C. (2015). Ad-hoc implicature in preschool children. Language Learning and Development, 11(2), 176-190.

Sullivan, J., \& Barner, D. (2016). Discourse bootstrapping: Preschoolers use linguistic discourse to learn new words. Developmental Science, 19(1), 63-75.

Sullivan, J., Boucher, J., Kiefer, R. J., Williams, K., \& Barner, D. (2019). Discourse coherence as a cue to reference in word learning: Evidence for discourse bootstrapping. Cognitive Science, 43(1), e12702.

Szufnarowska, J., Rohlfing, K. J., Fawcett, C., \& Gredebäck, G. (2014). Is ostension any more than attention? Scientific Reports, 4, 5304. 
Tempelmann, S., Kaminski, J., \& Liebal, K. (2013). When apes point the finger: Three great ape species fail to use a conspecific's imperative pointing gesture. Interaction Studies, 14(1), 7-23.

Tessler, M. H., \& Goodman, N. D. (2019). The language of generalization. Psychological Review, 126(3), 395-436.

Tincoff, R., \& Jusczyk, P. W. (1999). Some beginnings of word comprehension in 6-month-olds. Psychological Science, 10(2), 172-175.

Tomasello, M. (1995). Joint attention as social cognition. In C. Moore \& P. J. Dunham (Eds.), Joint attention: Its origins and role in development(pp. 103-130). Taylor \& Francis.

Tomasello, M. (2000). Do young children have adult syntactic competence? Cognition, 74(3), $209-253$.

Tomasello, M. (2003). Constructing a language. Cambridge : Harvard University Press.

Tomasello, M. (2008). Origins of human communication. Cambridge: MIT press.

Tomasello, M., \& Farrar, M. J. (1986). Joint attention and early language. Child Development, 57(6), 1454-1463.

Vouloumanos, A., Martin, A., \& Onishi, K. H. (2014). Do 6-month-olds understand that speech can communicate? Developmental Science, 17(6), 872-879. 
Vouloumanos, A., Onishi, K. H., \& Pogue, A. (2012). Twelve-month-old infants recognize that speech can communicate unobservable intentions. Proceedings of the National Academy of Sciences, 109(32), 12933-12937.

Walle, E. A., \& Campos, J. J. (2014). Infant language development is related to the acquisition of walking. Developmental Psychology, 50(2), 336-348.

Waxman, S. R., \& Gelman, S. A. (2009). Early word-learning entails reference, not merely associations. Trends in Cognitive Sciences, 13(6), 258-263.

Waxman, S. R., \& Markow, D. B. (1995). Words as invitations to form categories: Evidence from 12-to 13-month-old infants. Cognitive Psychology, 29(3), 257-302.

Wittgenstein, L. (1953). Philosophische untersuchungen. Frankfurt: Suhrkamp.

$\mathrm{Xu}, \mathrm{F}$. (2002). The role of language in acquiring object kind concepts in infancy. Cognition, $85(3), 223-250$.

Yoon, E. J., \& Frank, M. C. (2019). The role of salience in young children's processing of ad-hoc implicatures. Psyarxiv.com/8p67h. https://doi.org/10.31234/osf.io/8p67h

Yoon, E. J., \& Frank, M. C. (in press). The role of salience in young children's processing of ad-hoc implicatures. Journal of Experimental Child Psychology.

Yoon, E. J., Frank, M. C., Tessler, M. H., \& Goodman, N. D. (2018). Polite speech emerges from competing social goals. Psyarxiv.com/67ne8. https://doi.org/10.31234/osf.io/67ne8 
Yurovsky, D., \& Frank, M. C. (2017). Beyond naïve cue combination: Salience and social cues in early word learning. Developmental Science, 20(2), e12349.

Yurovsky, D., Case, S., \& Frank, M. C. (2017). Preschoolers flexibly adapt to linguistic input in a noisy channel. Psychological Science, 28(1), 132-140.

Zhao, S., Zhou, P., Ren, J., \& Frank, M. C. (in prep). Mandarin children's interpretation of implicatures and inference. 